\title{
O gasoduto Coari-Manaus e as perspectivas de desenvolvimento para o interior do Amazonas: algumas recomendações"
}

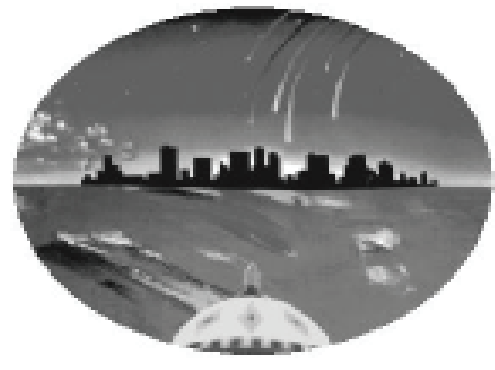

Isaque dos Santos Sousa

\section{Resumo}

O artigo discute como o gasoduto Coari-Manaus pode auxiliar no desenvolvimento do interior do Amazonas, a partir das potencialidades identificadas nos municípios na sua área de influência. As discussões são sobre Iranduba e Manacapuru pela proximidade e influência que ambos recebem da capital. Assim, recomendam-se algumas ações fundamentais para o desenvolvimento social e ambiental nesses municípios.

Palavras-Chave: Planejamento Urbano-Regional. Desenvolvimento. Gasoduto Coari-Manaus.

\begin{abstract}
The article discusses how the Coari-Manaus gas pipeline can help in developing the State of Amazonas rural area by using the potentialities identified in the surrounding areas under its influence. The discussions involve Iranduba and Manacapuru due to the proximity and the influence that the capital has over

\footnotetext{
* Elaborado a partir da Dissertação de Mestrado "Potenciais impactos do gasoduto Coari-Manaus no município de Manacapuru - AM”. Florianópolis, 2007. Com orientação do Prof. Dr. Carlos Loch. Programa de Pós-Graduação em Arquitetura e Urbanismo da Universidade Federal de Santa Catarina. Bolsa da Fundação de Amparo à Pesquisa do Estado do Amazonas - FAPEAM.

** Geógrafo, Mestre em Arquitetura e Urbanismo, Pesquisador Visitante no Instituto Leônidas e Maria Deane ILMD/FIOCRUZ.
} 
both of them. Thus, some effective actions are recommended for the social and environmental development of these municipal districts.

Keywords: Urban Regional Planning. Development. Coari-Manaus Gas Pipeline.

\section{Introdução}

O Estado do Amazonas possui o segundo maior contingente populacional da região Norte, conforme números do Instituto Brasileiro de Geografia e Estatística - IBGE. Em 2005 sua população total já ultrapassava os 3,2 milhões de habitantes, mas devido sua expressiva extensão territorial de 1,5 milhões de $\mathrm{km}^{2}$, sua densidade demográfica é de apenas $1,79 \mathrm{hab} / \mathrm{km}^{2}$. Aproximadamente $75 \%$ da população vivem nas cidades, especialmente em Manaus, que concentra o poder econômico-industrial da Região Norte brasileira.

O desenvolvimento econômico e social no Estado do Amazonas tem sido promovido pela presença da Zona Fraca de Manaus - ZFM. Este modelo, implantado pelo Governo Federal, na década de 1960, caracteriza-se pela isenção fiscal, o que atrai a instalação de indústrias diversas na região. Os objetivos eram de viabilizar uma base econômica na Amazônia Ocidental, promover melhor integração produtiva e social dessa região com o país e garantir a soberania nacional sobre suas fronteiras, conforme muito divulgado durante o Governo Militar.

Com a Zona Franca foram criados em Manaus um distrito agropecuário, um distrito comercial (no centro da cidade) e um distrito industrial, mas apenas este último permanece com sucesso. A Superintendência da Zona Franca de Manaus - SUFRAMA, autarquia ligada ao Ministério do Desenvolvimento e Comércio Exterior - MDIC e que administra esse importante pólo industrial do país, realiza feiras expositivas periodicamente que demonstram o potencial 
tecnológico e de mão-de-obra disponível no Amazonas; essa feira tem atraído investidores brasileiros e de outras nacionalidades.

Apesar do sucesso ao longo destes mais de 40 anos, a Zona Franca de Manaus não promoveu o desenvolvimento nos municípios interioranos; como prova disto tem-se uma elevada concentração populacional e conseqüentemente do comércio e serviços na cidade de Manaus, o que gera centralização econômica, política e social, enquanto os demais municípios do Estado permanecem com baixos índices de desenvolvimento. A falta de energia elétrica é o principal problema dentre as dificuldades encontradas.

Não se pode desconsiderar que a Zona Franca de Manaus também tem contribuído para a preservação das florestas no interior do Estado, como explica Berta Becker (2005, p. 83); como conseqüência tem-se a concentração de toda força produtiva apenas na capital, Manaus. Isso, por um lado, até poderia ser positivo; por outro lado, transformou a região em refém da renovação das licenças de funcionamento da Zona Franca. Daí a importância e necessidade de se pensar o desenvolvimento no interior do Estado, a partir de suas potencialidades endógenas.

Na discussão sobre o desenvolvimento de uma região é imprescindível conhecer as condições existentes, ou seja, é necessário reconhecer o meio técnico, científico e informacional, conforme expressa Milton Santos (2008). No caso do Amazonas, a pouca infra-estrutura nos municípios do interior tem influenciado no baixo desenvolvimento ou nas condições para que ele ocorra. A instalação de redes de serviços, por sua vez, especialmente de energia elétrica, esbarra diante do isolamento das localidades, isto é, da baixa densidade demográfica, característica inerente ao interior do Estado. Tal condição inibe possíveis empreendimentos e dificulta até mesmo melhorias infra-estruturais (POZZOBON; LIMA, 2005).

Neste sentido, a ação do Governo Militar de incentivar o povoamento da Amazônia estaria correta? Seria a melhor alternativa? Os imigrantes estariam prontos a se adaptarem às condições ambientais na/da região? Como essa política 
subsistiria se perdurasse na atual conjuntura dos movimentos ecológicos contra o desmatamento e pela preservação da floresta? Diante destas questões, as quais não serão esgotadas neste texto, questiona-se ainda como o desenvolvimento social, econômico e ambiental pode se dar no interior amazonense? Incentivar e investir nas potencialidades regionais são as melhores alternativas latentes.

\section{Energia elétrica para desenvolver as potencialidades regionais}

A energia elétrica no Estado do Amazonas é uma das mais caras do Brasil, pois ela é gerada em sistemas isolados ${ }^{1}$, normalmente abastecidos com óleo diesel (ROSA, 2007, p. 56), o que encarece e dificulta os empreendimentos de quase toda natureza.

Com a descoberta de petróleo e gás na região de Urucu, a crença de que o interior do Estado venha a se desenvolver tem sido muito forte, pois a mudança da fonte energética para uma matriz de menor custo operacional pode atrair diversos empreendimentos, contribuindo para desenvolvimento econômico local-regional; entretanto primeiramente é fundamental fazer com que o gás chegue aos centros urbanos, onde estão instalados os principais consumidores de eletricidade.

Conforme Camargo et al. (2004, p. 318) a geração e distribuição de energia elétrica para uma cidade ou região são fundamentais para o desenvolvimento. No Brasil, por exemplo, as regiões Sudeste e Sul do país destacam-se no cenário nacional, não apenas economicamente, mas nas diferentes áreas, seja na política, nas artes, na educação, na concentração industrial. Seria coincidência a densa rede de energia nesses Estados?

José Goldemberg (2000, p. 91-93) também concorda com essa interpretação de que a energia é um ingrediente essencial para o desenvolvimento, entretanto, adverte: a maioria dos equipamentos e processos utilizados nos dias de hoje nos setores de transporte, industrial e residencial foi desenvolvida numa época de energia abundante e barata e quando as preocupações ambientais ou não 
existiam ou eram pouco compreendidas. Nesse sentido, ao refletir sobre os processos e projetos de desenvolvimento do interior do Amazonas, atenta-se para as questões da energia elétrica e das preocupações com o meio ambiente na área em estudo.

Assim, com a construção do gasoduto Coari-Manaus busca-se atender pelos menos três prerrogativas: a primeira é levar o gás aos centros consumidores, sendo Manaus o principal deles; a segunda prerrogativa diz respeito a uma questão fundamental, que é a redução da degradação ambiental quando comparada ao sistema atual de termelétricas abastecidas com óleo diesel; uma terceira prerrogativa, muito ligada à anterior, trata da melhoria da qualidade do sistema de geração de energia elétrica sem, no entanto, torná-lo em preços inacessíveis.

$\mathrm{O}$ trajeto por onde se instalou o gasoduto pode ser visualizado na figura 1. Os municípios abrangidos pela obra são: Coari, Codajás, Anori, Anamã, Caapiranga, Manacapuru, Iranduba e Manaus.

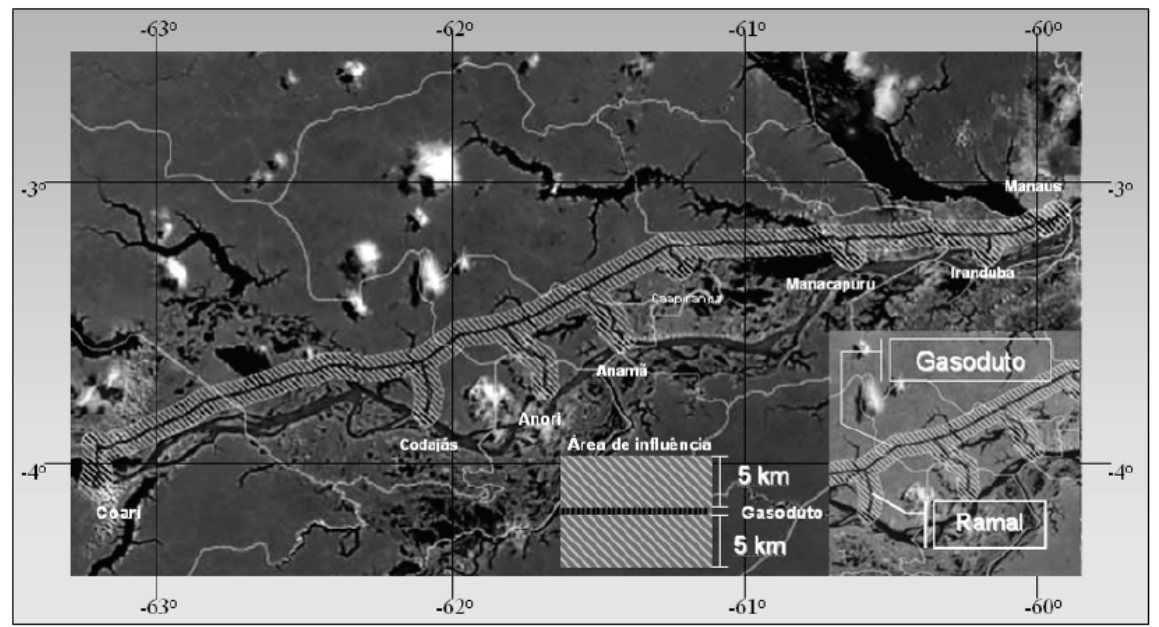

Figura 1 - Área de influência do gasoduto Coari-Manaus. Imagem LANDSAT-7/ETM+, 2003. Organização do Autor. 
A área considerada de influência direta abrange uma faixa de $10 \mathrm{~km}$, sendo $5 \mathrm{~km}$ de cada lado do gasoduto. No caso do município de Manacapuru, o Plano Diretor Municipal, aprovado em 2007, sugere a criação de uma faixa de preservação ambiental ao longo da margem da obra, atenuando-se os impactos ambientais admitidos e propiciados pela construção e implantação da obra. Estas mudanças não podem ser compreendidas como estritamente ao meio natural, daí a necessidade de discutir o empreendimento quanto à sua contribuição para o desenvolvimento, no sentido amplo deste termo.

Neste sentido, entende-se que a construção do gasoduto deve significar não apenas o levar energia para o interior do Amazonas, o que por si já é um significativo avanço, mas também propiciar o desenvolvimento em âmbito regional - local, sobretudo nos municípios localizados na sua área de influência. Mas, para que isto aconteça, são necessários alguns investimentos conforme as potencialidades dos municípios, levando essencialmente a infra-estrutura, como se discute adiante.

O orçamento da União para o ano de 2007 revelou haver consenso sobre a necessidade de se investir na oferta de energia elétrica como um dos principais caminhos para permitir o crescimento econômico da Região Norte brasileira. Conforme noticiado pelo jornal Diário do Amazonas, em novembro de 2006, “a maior parte dos investimentos para a Região concentra-se no setor de produção de energia [...] dos $\mathrm{R} \$ 7,7$ bilhões destinados à Região Norte, está prevista uma verba de $\mathrm{R} \$ 800$ milhões para o custeio e investimentos na Eletronorte”. O gasoduto Coari-Manaus é a principal destas obras que, enquanto matriz energética, seu objetivo primário é a geração de energia de baixo custo, o que possibilita a implantação de indústrias ou quaisquer outros empreendimentos nos lugares situados ao longo de seu percurso.

Além dos recursos financeiros investidos, conta-se ainda com a alta tecnologia e a presença da mão-de-obra especializada que se instala na região. Oportunamente, as administrações locais, em parceria com a Petrobras - empresa 
responsável pela exploração e distribuição de gás e petróleo - devem elaborar e apresentar um plano de investimentos e de fomento aos potenciais investidores. O Plano Diretor Municipal, um dos instrumentos legais obrigatórios para municípios inseridos na área de influência de empreendimentos com significativo impacto ambiental, deve orientar os investimentos e o desenvolvimento urbano e rural do município. O Estatuto da Cidade estabelece também que o planejamento municipal deve ser elaborado com ampla participação popular.

O planejamento e a gestão participativa, desenvolvidos com o devido rigor democrático e técnico, são uma importante alternativa para racionalizar o uso dos recursos disponíveis e evitar equívocos já experimentados na exploração das riquezas existentes na região. A economia amazonense, até o início do século XX, foi baseada no extrativismo vegetal, com a exploração do látex, e viveu seu apogeu com o ciclo da borracha ${ }^{2}$. Houve grandes investimentos na vida econômica e sociocultural na região; o Teatro Amazonas é o símbolo maior desse momento histórico social. Contudo, as glórias adquiridas não foram capazes de impulsionar o desenvolvimento intra-regional, possivelmente porque se tratava apenas da retirada de um recurso, sem programar sua utilização na região.

A atividade mineral no Estado do Amazonas ainda é irrelevante, a exploração de metálicos é praticamente restrita à mina de cassiterita (estanho) e columbita-tantalita (nióbio e tântalo) do Pitinga, operada pela Mineração Taboca do Grupo Paranapanema. Conforme dados do Departamento Nacional de Produção Mineral - DNPM, em 2001 o Estado teve uma movimentação financeira na ordem de $\mathrm{R} \$ 84$ milhões, enquanto que o Estado do Pará movimentou $\mathrm{R} \$ 6,6$ bilhões no mesmo período.

A importância do gasoduto Coari-Manaus também é compreendida pelo fato de que o processo de exploração de petróleo e dos seus derivados possui algumas características que o torna diferenciado de outros projetos pensados e implantados no Amazonas, os quais visavam à exportação dos bens e recursos 
naturais. O petróleo e o gás extraído serão utilizados/consumidos na própria região.

Em termos de preocupações ecológicas, pode-se dizer que houve um avanço em relação aos primeiros grandes projetos, porém, a falta de consenso entre a política de desenvolvimento econômico e a política de preservação ambiental têm como resultado o caráter focal, restrito à maximização dos objetivos econômicos imediatos dos projetos. Trata-se, portanto, de uma cultura ecológica instrumental e limitada, sem referência à globalidade dos sistemas ambientais afetados. (POZZOBON; LIMA, 2005, p. 66).

As mudanças socioespaciais, em função do processo da implantação de um gasoduto no interior do Amazonas, já puderam ser experienciadas, como avaliou Cáuper (2000), no município de Coari. Entretanto, as transformações que ocorrerão nos municípios do interior amazonense, sob influência direta do empreendimento, dependem também da reação preparada pelos agentes produtores locais, ou seja, os impactos ambiental, econômico e, especialmente, social dar-se-ão mediante a capacidade dos gestores locais receberem tais modificações, da capacidade de absorção dos impactos advindos, sejam eles positivos ou negativos.

Como se afirmou acima, a distribuição de energia numa dada região pode contribuir para seu desenvolvimento, pois, onde há uma rede de energia elétrica, haverá mais indústrias, possivelmente poder haver mais ofertas de emprego, o que atrai novos moradores e assim, necessitando de maior infra-estrutura social (CAMARGO et al. 2004). Portanto, de maneira paradoxal, os impactos sociais e ambientais dar-se-ão com maior intensidade, como acontece nas grandes cidades do Brasil, as quais em algum momento-espaço fazem lembrar a antiga Manchester industrial, descrita no texto de Engels (1987).

Ao pensar o pleno desenvolvimento acima referido, é essencial considerar também as condições de moradias para os novos habitantes que haverão de se instalar nas cidades em busca das melhorias preconizadas. 


\section{Significados e expectativas do gasoduto Coari-Manaus}

O gasoduto Coari-Manaus previsto para funcionar a partir de fevereiro de $2008^{3}$ terá a capacidade para escoar cerca de 5,5 milhões de metros cúbicos de gás natural por dia. O produto será destinado ao abastecimento de usinas termelétricas convertidas de óleo para gás e para atendimento às residências, às indústrias e à frota de veículos, especialmente táxis ${ }^{4}$ de Manaus.

Segundo informações disponibilizadas pela Petrobras, em Urucu, município de Coari-AM, está a maior Unidade de Processamento de Gás Natural do Brasil - UPGN do Brasil. Sua produção média de gás natural é de 10,36 mil metros cúbicos por dia. O processamento de Gás Liquefeito de Petróleo - GLP, por exemplo, supera 1,5 mil toneladas diárias, quantia esta equivalente a 115 mil botijas de $13 \mathrm{~kg}$ e tem abastecido os Estados do Pará, Amazonas, Rondônia, Maranhão, Tocantins, Acre, Amapá e parte do Nordeste.

Em matéria publicada no Jornal do Comércio (Manaus), no dia 5 de junho de 2006, o geólogo Daniel Borges Nava, então superintendente do Serviço Geológico do Brasil, afirmou que as reservas minerais, de óleo e de gás do Amazonas podem atender o país por 80 anos. Segundo ele, o contingente está concentrado em Urucu-Juruá, na Bacia do Solimões e, no município de Silves, a $283 \mathrm{~km}$ de Manaus.

\footnotetext{
Todas estas reservas somadas estão acima de 80 bilhões de $\mathrm{m}^{3}$. Se tivéssemos o gasoduto, poderíamos atender o Brasil em mais de 80 anos, considerando que o consumo interno atual é de 1 bilhão/ano", explica o superintendente. [...] Segundo Nava, não falta conhecimento tecnológico nem de matéria-prima. $\mathrm{O}$ problema é levar a produção mineral até o mercado, esforço este que está sendo realizado em conjunto com o governo do Estado e a Petrobras.
} 
A exploração do gás natural da bacia petrolífera de Urucu, tendo como mercado consumidor a capital e mais algumas cidades do interior, constitui-se numa via oportuna para o desenvolvimento do interior amazonense. Mas, para tanto, torna-se necessário atentar à melhor maneira de como isso será explorado, de que forma serão distribuídos os bônus e os ônus naquelas localidades por onde passa o gasoduto.

Para a sociedade local, isto é, para aquelas pessoas que moram na área de influência, sua preocupação maior quanto às possíveis transformações sociais decorrentes da implantação da obra é saber quanto e como suas condições de vida poderão ser melhoradas a partir do empreendimento. Esse sentimento reflete o quão carentes de melhorias infra-estruturais se encontram estas localidades. Com isso, entende-se que o desenvolvimento carece da instalação e funcionamento de boas escolas, de mudanças na saúde coletiva, da geração de renda e valorização cultural por meio do incentivo à criatividade pessoal-local, do respeito ao meio ambiente e, assim, das melhorias na qualidade de vida.

É evidente que a filosofia de desenvolvimento de quaisquer investimentos aplicados deve estar à altura da realidade socioeconômica local e regional, e isto implica que nem sempre se podem aplicar as mesmas concepções de desenvolvimento experimentadas noutras regiões do país.

Quanto ao setor de transportes, acredita-se que este também poderá ganhar novos horizontes com a utilização do Gás Natural Veicular - GNV, com a redução de custo e maior rendimento para os proprietários, e estes valores precisam ser repassados aos clientes e usuários do sistema de transportes e, em se tratando do interior do Estado, especialmente às embarcações regionais.

Conforme informou, via correio eletrônico, Paulo César de Oliveira Lima - engenheiro mecânico da PETROBRAS, “a utilização do GNV Puro nas embarcações ainda não é viável por questões de tecnologia e logística para abastecimento", no entanto, a empresa tem apoiado "o projeto de um navio para transporte de passageiros e automóveis com tecnologia bi-combustível 
(gás natural + óleo diesel)". Lamentavelmente, não se percebeu até o momento nenhum projeto ou movimentação para que as embarcações no Amazonas passem por adaptações a fim de se utilizarem deste combustível também.

No Amazonas, uma especificidade regional atrai a atenção dos especialistas: o setor fluvial. Como os rios substituem as estradas, está sendo estudada a conversão de motores de grandes embarcações para uso do GNV. Atualmente estão registradas no estado 32.423 embarcações. (PETROBRAS, 2005, p. 7).

Em realidade, as condições do transporte fluvial no Amazonas não têm recebido a devida atenção das autoridades políticas ou dos gestores técnicos. A construção, usos e manutenção das mesmas parecem não ter fiscalização por parte dos setores competentes. A precariedade do sistema somente é discutida quando acontecem grandes acidentes, vitimando dezenas de pessoas.

Considerar as condições físico-geográficas, as ações políticas e atentar, sobretudo, às especificidades do território é fundamental para quaisquer programas ou propostas de desenvolvimento de uma região. Também não há como dissociar o ambiental do social, pois o meio ambiente é o resultado dessa constante inter-relação.

O meio ambiente é o produto da interação entre os homens e a natureza e da intervenção entre os próprios homens, em espaços e tempos concretos e com dimensões históricas e culturais específicas que expressam também o significado político e econômico das mudanças que se pretende induzir ou sustar (RATTNER, 1992, p. 63).

Os atores sociais envolvidos no processo de implantação do gasoduto e de outros empreendimentos que o mesmo possa atrair precisam estar sensibilizados ao fato de que o uso extensivo dos recursos naturais, especialmente se não há manejo, é extremamente nocivo ao ambiente. Atenta-se para isto porque, infelizmente, o discurso oficial e burocrático projeta o desenvolvimento sustentável numa dimensão essencialmente ecológica, como adverte Freitas 
(2003), deslocando-o da tessitura social. No limite, quando ele imprime historicidade a esta noção, refere-se às gerações futuras. É preciso que haja uma linguagem sistêmica e integradora que articule os processos da natureza com a cultura nas escalas espaciais e temporais.

Apesar de tudo, algumas expectativas de melhorias nas cidades poderão se concretizar quando os ramais de gás para os municípios na área de influência direta do gasoduto estiverem concluídos e as usinas termelétricas para geração de energia elétrica estiverem em pleno funcionamento. Os ramais para cada cidade representam um investimento de $\mathrm{R} \$ 70$ milhões e foram previstos no estudo para a aprovação do Relatório de Impacto Ambiental do empreendimento.

Paralelamente aos ramais também se planeja implantar uma rede de fibra ótica, interligando com alta tecnologia de informação as cidades na área de influência do empreendimento. Caso isto se concretize, certamente será um salto tecnológico que criará diversas oportunidades aos moradores das cidades na área de influência, como a possibilidade da instalação de outras redes de serviços tais como educação à distância, atendimento médico, acesso à internet e à telefonia de alto desempenho.

Portanto, a expectativa é do aumento do consumo de energia, mas também de uma melhoria do bem-estar da população local, por meio dos serviços que serão gerados pela energia elétrica disponibilizada, como explica Goldemberg (2005, p. 215): “o propósito para o qual os serviços energéticos são alocados é que determina, em última análise, o nível de desenvolvimento econômico atingido".

\section{Potencialidades dos municípios da área de influência - exemplo de Manacapuru}

A condição físico-geográfica dos municípios localizados na área de influência situa-os todos de maneira similar, quando se observa numa escala 
pequena; localizados em terrenos de várzea, banhados pelo rio Solimões e alguns de seus afluentes, mas basta uma aproximação, aumentando a escala de análise, para verificar as dessemelhanças, ou melhor, a diversidade entre os lugares alcançados pelo gasoduto. A proximidade de um centro produtor, a exploração de algum recurso natural, como a argila, tem possibilitado transformações econômicas, sociais e demográficas, como se verifica nas cidades de Iranduba e Manacapuru.

Neste segundo município, a impressão que se teve em muitos dos lugares visitados foi a de que há diversas potencialidades para o desenvolvimento local que podem ser trabalhadas, mas em todos os casos um dos elementos inibidores são as condições de infra-estrutura existentes, isto é, sistema de transportes, abastecimento d'água, energia elétrica, escolas e atendimento em saúde.

$\mathrm{Na}$ maioria das cinqüenta comunidades de Manacapuru, se poderia incentivar e conceber cooperativas visando ao beneficiamento da fibra de juta, para a confecção de produtos artesanais, beneficiamento do pescado e dos frutos regionais (açaí, cupuaçu), pois normalmente estes produtos são vendidos na sua forma in natura, sem antes agregar valor.

No caso do pescado, conforme Gonçalves e Batista (2008, p. 144), a viabilidade do setor de recursos pesqueiros pode se iniciar com a criação de mecanismos de gerenciamento das atividades com a cumplicidade dos usuários. Portanto, o ideal é que para cada setor os gerenciadores estejam integrados a todo o sistema de produção ou beneficiamento. Estas atitudes, para além de aumentar a margem de lucro na comercialização dos produtos, beneficiariam os trabalhadores rurais moradores nas comunidades de onde se extraem os produtos com a geração de empregos.

Também se observou em campo que o município de Manacapuru possui um rico potencial para a produção de farinha de mandioca, mas muitas comunidades sequer têm forno para torrar a massa. No Amazonas, independente da estação do ano, a mandioca é a principal fonte da dieta cabocla (ADAMS et al. 
2005); por isso, mais uma vez se enfatiza a necessidade de melhorar as condições de produção nessas localidades e, evidentemente, buscar parceiros a quem será destinada essa produção que, por sua vez, precisa ter boa qualidade do produto e melhores condições no sistema de transportes.

Conforme dados da Secretaria de Estado da Produção Rural - SEPROR, a demanda por farinha de mandioca no Amazonas é de oito mil toneladas por mês; desse total, sete mil toneladas são para o Distrito Industrial e o restante abastece o setor de alimentação. Entretanto, as empresas do Pólo Industrial de Manaus - PIM compram fécula de mandioca do Estado do Paraná. Ora, as razões para essa atitude podem ser diversas; entretanto, é inaceitável que seja pelo simples fato dos produtores locais não oferecerem o produto em quantidade e qualidade conforme a demanda. Sendo as razões de ordem infra-estrutural, como transportes e energia, este quadro precisa ser urgentemente mudado.

Nos municípios de Iranduba e Manacapuru, concentra-se um dos principais pólos do setor oleiro-cerâmico da Região Norte brasileira. As muitas olarias desta área poderão ser beneficiadas com a utilização do gás natural no abastecimento dos fornos, condição esta que, inclusive, pode reduzir a extração de madeiras usadas como lenhas e contribuir na preservação do meio ambiente. Neste caso, os impactos ambientais causados pelo setor oleiro se concentrariam na retirada de argila, atividade esta carente de um plano de manejo urgente, haja vista as muitas valas encontradas à beira da Rodovia Manuel Urbano estrada que liga Manaus a Manacapuru. O gás natural nessa região será muito importante no setor industrial já existente, mas também outros setores precisam ser incentivados.

\section{Considerações finais}

O desenvolvimento do interior amazonense passa pela compreensão da realidade socioeconômica local, pela identificação da capacidade de absorção ou recebimento das transformações advindas com os empreendimentos previstos 
e almejados. Estas ações poderão contribuir na eficácia das políticas públicas e de gestão a serem implantadas; contudo, somente ocorrerão mudanças positivas mediante algumas iniciativas expostas a seguir:

Incentivar a instalação de pequenas indústrias que busquem agregar valor aos produtos regionais, dando prioridade às frentes pioneiras locais, como o beneficiamento do açaí, do cupuaçu, da castanha e da juta a fim de consolidar as iniciativas existentes. Um caminho possível é a organização de cooperativas de trabalhadores. Também é fundamental organizar e disponibilizar, possivelmente em pólos de desenvolvimento, serviços do sistema público, conforme as demandas sociais identificadas; refere-se a postos de saúde, escolas, postos bancários, postos policiais etc.

A prefeitura e a câmara de vereadores precisam traçar planos para a atração de investimentos; devem buscar parcerias com agências de fomentos com vistas à concessão de créditos aos pequenos produtores locais. Em realidade, é necessário ainda que haja capacitações até mesmo para as lideranças (vereadores, presidentes de associações, secretários) sobre a captação de recursos, submissão e aprovação de projetos nos diversos órgãos financiadores de projetos sociais. Muitas vezes se tem a idéia, os editais estão abertos, os recursos estão lá, porém ninguém conhece os trâmites legais para captação do recurso e liberação das verbas.

Outro ponto importante para o pleno desenvolvimento no interior do Amazonas diz respeito à qualificação profissional dos trabalhadores, pois, sem isto, os mesmos não serão admitidos nos diferentes empregos que possam vir a ser criados; não assumirão as distintas ocupações que as empresas possam precisar. Sem a devida preparação, até estariam inseridos no processo produtivo, porém, apenas como mão-de-obra não-qualificada.

A qualificação profissional da mão-de-obra local precisa atender a demandas de baixa, média e alta escolaridade, isto é, não basta treinar cozinheiros, copeiros e lavadeiras de roupas, mas devem ter cursos capacitando mecânicos, técnicos 
em distintas especialidades e profissionais graduados com nível superior, ou seja, deve-se investir na formação nos níveis médio e superior, por meio de parcerias com as escolas técnicas e instituições de ensino superior a fim de oferecer cursos profissionalizantes visando preparar a sociedade para os investimentos futuros.

Os cursos e treinamentos a serem realizados precisam ter, dentre outros objetivos, a padronização dos serviços urbanos, público ou particular, como em restaurantes, hotéis, escolas e atendimento ao turista; afinal, o desenvolvimento de uma cidade pode ser refletido na qualidade dos serviços oferecidos aos seus visitantes e especialmente aos moradores.

Com relação às cavas para a retirada de argila para uso nas olarias, nos municípios de Iranduba e Manacapuru, podem ser aproveitadas na piscicultura, desde que se façam as devidas adaptações. Por exemplo: o aprofundamento e tamanho necessário para implantação dos tanques, pois, na maioria dos locais de onde se retira a argila, as escavações são apenas de um metro de profundidade. Recomenda-se, ainda, que os órgãos de gestão ambiental do município possam monitorar a construção desses tanques bem como gerenciar os espaços destinados à retirada de argila, evitando-se a exploração indiscriminada de áreas.

Outro horizonte se aproxima: a construção da ponte sobre o rio Negro mudará completamente o processo de reprodução social e espacial de Manacapuru e Iranduba; diante disso, o investimento em pesquisas humanas e sociais é também indispensável para o desenvolvimento da região. Seus resultados podem auxiliar as tomadas de decisões, apontando caminhos a serem seguidos e evitando-se cometer graves erros do passado.

\section{Notas}

${ }^{1}$ A geração de energia elétrica em sistemas isolados é subsidiada pela União através da Conta de Consumo de Combustível Fosseis - CCC. Este imposto 
representa $\mathrm{R} \$ 3,3$ bilhões por ano; o mesmo é pago por todos os consumidores de energia no país.

${ }^{2} \mathrm{O}$ ciclo da borracha constituiu uma parte importante da história econômica e social do Brasil, estando relacionado com a extração e comercialização da borracha. Este ciclo teve o seu centro na região amazônica, proporcionando grande expansão na colonização, atraindo riqueza e causando transformações culturais e sociais, além de dar grande impulso às cidades de Manaus, Porto Velho e, principalmente, à cidade de Belém, até hoje maiores centros e capitais de seus Estados: Amazonas, Rondônia e Pará, respectivamente. O ciclo da borracha viveu seu auge entre 1879 a 1912, tendo depois experimentado uma sobrevida entre 1942 a 1945.

${ }^{3}$ Este prazo foi previsto antes do início das obras, em junho de 2006. Depois disso, já houve mudanças no cronograma de execução, como abril de 2008, mas também não foi cumprido.

${ }^{4}$ Em Manaus, já tem táxis funcionando a gás, porém são apenas alguns, que fazem parte de um programa experimental, cujo objetivo é realmente disponibilizar esse tipo de combustível a todos os consumidores.

\section{Referências}

ADAMS, C.; MURRIETA, R. S. S.; SANCHES, R. A. Agricultura e alimentação em populações ribeirinhas das várzeas do Amazonas: novas perspectivas. Revista Ambiente Sociedade. v. 8, n. 1, p. 65-86, jan./jun. 2005. ISSN 1414-753X.

BECKER, B. K. Geopolítica da Amazônia. Revista de Estudos Avançados. 2005, v. 19, n. 53, p. 71-86. ISSN 0103-4014.

CAmargo, A.; CAPOBIANCO, J. P. R.; et al. (org.) Meio ambiente Brasil avanços e obstáculos pós-Rio 92. São Paulo: FGV - ISA. 2004. 
CÁUPER, G. C. de B. A Influência das atividades de exploração de petróleo e os impactos ambientais e socioeconômicos na cidade de Coari. Mestrado (Dissertação). Centro de Ciências Ambientais - UFAM. Manaus, 2000.

PÓLO CERÂMICO FATURA R\$25 MILHÕES AO ANO Jornal do Commercio. Manaus, 5 de junho de 2006.

AMAZONAS PRECISA DE ENERGIA PARA CRESCER. Jornal Diário do Amazonas. Caderno de Economia, Manaus, 13 de novembro de 2006.

ENGELS, F. A situação da classe trabalhadora na Inglaterra. 2. ed. Lisboa, Presença, 1987.

FREITAS, M. de. Nuanças da sustentabilidade: visões fantásticas da Amazônia. Cadernos do CEAS, 207, p. 111-132, Salvador, Centro de Estudos e Ação Social, set.-out., 2003.

GOLDEMBERG, J.; MOREIRA, J. R. Política energética no Brasil. Revista de Estudos Avançados, set./dez. 2005, v. 19, n. 55, p. 215-228. ISSN 0103-4014.

GOLDEMBERG, J. Pesquisa e desenvolvimento na área de energia. São Paulo Perspec., v. 14, n. 3, p. 91-97. jul./set. 2000. ISSN 0102-8839.

GONÇALVES, C.; BATISTA, V. da S. Avaliação do desembarque pesqueiro efetuado em Manacapuru, Amazonas, Brasil. Revista Acta Amazônica, v. 38(1), p. 135-144. 2008.

LIMA, P. C. de O. Orientação Técnica [REF:3536191882]. E-mail recebido em 18 de agosto de 2008. Serviço de Atendimento ao Cliente, PETROBRAS.

PETROBRAS. Amazônia: o caminho da energia no coração da floresta. Cadernos Petrobras. Ano 5, n. 5, dez/2005.

PETROBRAS. Produção e abastecimento - Petróleo da província de Urucu é de alta qualidade. Disponível em <http://www2.petrobras.com.br/minisite/urucu/03. swf>. Acesso em: 13/08/2008. 
POZZOBON, J.; LIMA, D. Amazônia socioambiental sustentabilidade ecológica e diversidade social. Revista de Estudos Avançados 19 (54), 2005.

RATTNER, H. Contabilização econômica do meio ambiente. São Paulo: Governo do Estado de São Paulo. 1992.

ROSA, L. P. Geração hidrelétrica, termelétrica e nuclear. Revista de Estudos Avançados. v. 21, n. 59, p. 39-58. jan./abr. 2007. ISSN 0103-4014.

SANTOS, M. A natureza do espaço: técnica e tempo, razão e emoção. 4. ed. $4^{a}$ reimp. São Paulo: EDUSP. 2008. 